\title{
A representatividade como estímulo à retenção de conhecimentos: uma dinâmica possível para a aprendizagem significativa ${ }^{1}$
}

\author{
Maria Raidalva Nery Barreto ${ }^{2}$ \\ Luciana Aquino Ribeiro ${ }^{3}$ \\ José Roberto Tavares Sampaio
}

Resumo: Pormenorizar os processos de aquisição do conhecimento é um desafio para pesquisadores das distintas áreas. Considerando a aprendizagem um fenômeno que comporta a amplitude social e cultural dos indivíduos, as vivências no decorrer da história pessoal podem firmar um conjunto conceitual que permite aquisição e retenção de conhecimento. Este artigo tem como objetivo avaliar a representatividade da identidade culturalmente negra como ideia-âncora que contribui para a retenção de conhecimentos de alunos da graduação oriundos da periferia de Salvador. A pesquisa de natureza exploratória e empírica está fundamentada sob a perspectiva da aprendizagem significativa, proposta por David Ausubel (2001). Utiliza como amostra alunos da graduação em Comunicação Social da UNIFTC Campus Paralela, no período de agosto a dezembro de 2018, a partir do projeto gráfico elaborado para uma revista impressa. Legitimar o processo de afirmação da identidade étnico racial durante a experiência acadêmica potencializa a aprendizagem sendo possível contribuir com uma sociedade multicultural.

Palavras-chave: Aprendizagem significativa. Ideia-âncora. Identidade. Representatividade. Retenção de conhecimento.

\section{Representativeness as a stimulus for knowledge retention: a possible dynamic for a meaningful learning}

Abstract: Detailing the knowledge acquisition processes is a challenge for researchers from different areas. Considering learning as a phenomenon that encompasses the social and cultural breadth of individuals, experiences throughout personal history can establish a conceptual set that allows knowledge acquisition and retention. The objective of this article is to evaluate

\footnotetext{
${ }^{1}$ Artigo apresentado à disciplina de Metodologia dos Processos Cognitivos.

2 Doutora em Educação e Contemporaneidade pela UNEB (2017), com estágio doutoral pela USP; Mestre em Políticas Públicas, Gestão do Conhecimento e Desenvolvimento Regional pela UNEB (2009); Mestre em Ciência da Educação pela Universidade Lusófona de Humanidade e Tecnologia (2004); Graduada em Pedagogia (UNEB/1984), Docente do IFBA. Docente no Curso de Doutorado Multi-Institucional e Multidisciplinar em Difusão do Conhecimento (UFBA/IFBA/UNEB/SENAI-CIMATEC/LNCC/UEFS). E-mail: raibarreto@gmail.com

3 Luciana Aquino Ribeiro é aluna especial do Doutorado Multiinstitucional e Multidisciplinar em Difusão do Conhecimento do IFBA / UFBA / UNEB. E-mail: profaluaquino@gmail.com

4 José Roberto T. Sampaio é aluno especial do Doutorado Multiinstitucional e Multidisciplinar em Difusão do Conhecimento do IFBA / UFBA / UNEB. E-mail: robertofacex@hotmail.com
} 
representativeness as a key concept for retaining knowledge of undergraduate students from the outskirts of Salvador. The research of exploratory and empirical nature is based on the perspective of significant learning, proposed by David Ausubel (2001). It uses as a sample students from the undergraduate degree in Social Communication at UNIFTC Campus Paralela, from august to december 2018, from the graphic design developed for a magazine. The identity concepts based on the social movement promote awareness and critical sense of young people from the periphery who enter higher education and must be reflected in the academic experience in order to enhance learning.

Keywords: Meaningful learning. Anchor idea. Identity. Social movement.

\section{Introdução}

Compreender como ocorrem os processos de aquisição do conhecimento continua a ser um desafio para a ciência. A fim de elucidar caminhos, pesquisadores das distintas áreas desenvolveram teorias que consideram diferentes perspectivas para dar conta da experiência da aprendizagem.

Em geral, os jovens do século XXI, superestimulados pelo acesso às diferentes culturas, instantaneidade da notícia e oferta de tecnologias da informação e da comunicação - TIC's vivenciam uma interação com o mundo que impacta diretamente a sala de aula, tornando-se um obstáculo à aprendizagem.

Por outro lado, o acesso às tecnologias emergentes permite que esses jovens se tornem autores de suas próprias narrativas. Em particular, os jovens da periferia que ingressam no ensino superior, no curso de Comunicação Social, anseiam projetar uma dinâmica de valores culturais pautadas na representatividade da cultura periférica nos diversos produtos gráficos e audiovisuais realizados durante o curso, sendo esta uma necessidade legítima de expressão.

Este artigo tem por objetivo avaliar a representatividade cultural como ideia-âncora que contribui para retenção de conhecimentos. O reforço das representações da identidade e o senso crítico dos jovens periféricos são potencialmente significativos para a experiência acadêmica e estimulam processos de aprendizagem.

A pesquisa de natureza exploratória e empírica está fundamentada sob a perspectiva da aprendizagem significativa, proposta por David Ausubel (2001). Utiliza como amostra alunos da graduação em Comunicação Social da UNIFTC Campus Paralela, no período de agosto a dezembro de 2018. 
O projeto desenvolvido pelo grupo de alunos do $6^{\circ}$ semestre de Comunicação Social foi realizado no âmbito da disciplina Planejamento, Editoração e Diagramação e teve como proposta a elaboração de uma revista temática de vinte e quatro páginas, da concepção do tema até a sua versão impressa.

Enquanto fenômeno de amplitude social e cultural a aprendizagem compreende as experiências que incluem a história pessoal dos indivíduos. Para David Ausubel, a retenção de conhecimentos deve firmar um conjunto conceitual que permita aprendizagem significativa. Acredita-se que, ao utilizar a representatividade cultural como ideia-âncora para retenção de conhecimentos, as estratégias de ensino conduzem à assimilação de novos conteúdos.

\section{Desenvolvimento}

\subsection{Aprendizagem significativa}

Enquanto proposta cognitiva, que considera o armazenamento das informações em um conjunto organizado denominado estrutura cognitiva, para haver aprendizagem significativa o indivíduo deve estar disposto a aprender (AUSUBEL, 2001).

A noção de disposição distancia esta aprendizagem dos processos mecânicos, a exemplo da memorização. Ao contrário da passividade, a aprendizagem significativa é um processo dinâmico, que ocorre quando são integrados novos conhecimentos àqueles já previamente adquiridos na estrutura cognitiva dos sujeitos (MOREIRA, 2006). Por se tratar de um processo mental, distingue-se conceitualmente do sentido externo e observável de outras abordagens (RIHS; ALMEIDA, 2017).

O contexto educacional é a base para que haja aprendizagem de novos conceitos e segundo esta teoria há três tipos de aprendizagem significativa: representacional, aquela que associa palavras a objetos ou símbolos; de conceitos, quando há aprendizagem do significado dos conceitos ou acontecimentos; proposicional, aquela que dá conta do significado de ideias expressas por grupos de palavras (proposições), presente nos mapas conceituais (AUSUBEL, 2003).

Para David Ausubel a existência de um conceito potencial na mente do aprendiz é o critério de classificação da aprendizagem significativa. Potencial porque ele deve ser capaz de sedimentar uma nova informação que permita modificar a estrutura cognitiva deste, influenciando a sua aprendizagem e, consequentemente, permitindo integração de saberes, novos 
e pré-existentes. O conhecimento pré-existente é designado ideia-âncora, um conceito ou proposição originalmente mais amplo, que interage como subordinador de outros conceitos servindo de ancoradouro durante a assimilação na estrutura (MOREIRA; MASINI, 1982).

Nesse contexto, a noção de ideia-âncora é o ponto de partida para a reconfiguração da estrutura cognitiva do aprendiz em um novo corpus organizado de conhecimento, ampliando suas possibilidades de interação e diálogo com o mundo.

$\mathrm{Na}$ ausência de ideias-âncora, Ausubel propõe o uso de organizadores prévios, que funcionariam como "pontes cognitivas" (MOREIRA, 1997) entre o que o aprendiz já sabe e o que precisa aprender. Trata-se de materiais introdutórios que precedem o conteúdo a ser trabalhado durante a aula, obrigatoriamente mais genéricos, e que possam ter ligação com algum conhecimento já adquirido para criar a condição ausubeliana de aprendizagem. São princípios norteadores da teoria da aprendizagem, de David Ausubel:

1) Os conteúdos devem seguir uma ordem de apresentação, de maior generalidade para, posterior e progressivamente, serem diferenciadas em termos da sua especificidade. Para Ausubel, os conceitos possuem hierarquia e se organizam do conteúdo mais relevante, a partir do seu grau de inclusividade, para aqueles que lhe são subordinados;

2) O material a ser aprendido deve ser potencial e psicologicamente significativo, tanto em relação à natureza do material, quanto à experiência do indivíduo, considerando que cada aluno realiza uma filtragem do conteúdo para reter o que lhe faz sentido;

3) Os materiais programáticos devem facilitar o processo de aprendizagem ao organizar a ordem de estudo e devem conter uma prévia informação introdutória utilizando comparações e referências cruzadas entre ideias novas e pré-existentes, para criar um marco de referência contextual.

Portanto, a manifestação do desejo para a aprendizagem é uma competência adquirida pelo sujeito que indica uma disposição para relacionar os conceitos de forma substantiva.

\subsection{Representatividade cultural}

Os estudos sobre representatividade estão fortemente relacionados ao conceito de identidade e este artigo não tem o intuito de cobrir todas as definições e reflexões presentes na literatura, o que exigiria diálogo mais aprofundado.

Entretanto, considerando seu objetivo, a pesquisa relaciona três premissas sobre a construção da identidade, sob o olhar do multiculturalismo crítico, que enfatiza a pluralidade 
cultural (CANEN, 2001): o sentido de construção contínua da identidade, tecida nas relações sociais, a presença de marcadores plurais, tais como "raça, etnia, gênero, histórias de vida, classes sociais, cultura e outros" (CANEN, 2001, p.51) e a pluralidade de identidades, que constituem a sociedade (grifo nosso).

Considerando que a cultura não é um bloco homogêneo, Hutcheon (1991) afirma que na sociedade contemporânea há uma pluralidade de centros de poder, pulverizando o que é considerado marginal (que está na margem). Significa que pensar os cenários sob pólos de oposição ‘centro versus margem’ é uma visão reducionista da realidade, cada vez mais distante quando considera-se a globalização tecnológica (HUTCHEON, 1991 apud SILVA, 2002).

A questão da representação torna-se um problema, especialmente quando a representação refere-se à cultura negra e à periferia, tratada sempre por uma única perspectiva que não reflete a sua totalidade, como explica Silva (2003):

A representação é como um retrato, uma imagem fixa que tenta descrever e resenhar como deve ser um determinado sujeito ou grupo. A representação não dá conta da pluralidade, dos diversos modos de vida e possibilidades estéticas. A lógica da representação tende a plasmar discursos correntes e se passa a presumir certas experiências como comuns e inerentes aos grupos. Essas imagens preconcebidas mesmo quando positivas tendem a ser limitadoras e totalizantes" (SILVA, 2013, p.52).

Para Silva (2013), a lógica da representação didatiza (grifo nosso) modos de existir e limita os repertórios existenciais, ao simplificar a variedade e multiplicidade presentes nos indivíduos contemporâneos e suas produções resultantes das hibridizações culturais.

O mais adequado é utilizar o termo representatividade, que dá visibilidade aos diversos modos de existência, sugerindo uma qualidade manifestada na integração de conceitos, sem pretensão de definir restritamente uma entidade, grupo ou pessoa, mas, sobretudo, revelar a diversidade contida nela.

\subsection{Projeto da revista}

A disciplina Planejamento, Diagramação e Editoração é ministrada no sexto semestre de Comunicação Social para os cursos de Publicidade e Propaganda e Jornalismo e tem por objetivo de aprendizagem capacitar o aluno para desenvolver projetos gráficos integrando a composição 
de elementos visuais e conteúdos na página impressa e eletrônica, compreendendo seus processos de criação e produção.

Os conhecimentos prévios de ordem técnica foram assimilados pelo grupo de alunos em disciplinas ministradas em semestres anteriores (Quadro 1): Direção de Arte I e II, Computação Gráfica, Semiótica, Introdução à Fotografia, Fotografia Publicitária, Fotojornalismo e Jornal Laboratório. Nesse contexto de aprendizagem foi apresentado o conjunto de conceitos necessários para o planejamento gráfico através de atividades práticas que revisaram e integraram os elementos visuais (cor, textura, tipologia, imagem, linhas, formas), a produção textual, o tratamento da imagem e os processos de produção gráfica, todos eles fundamentais para confecção da revista impressa.

O projeto gráfico teve por objetivo criar uma revista temática de vinte e quatro páginas sendo proposta a produção de todo o conteúdo pelos alunos integrantes das equipes: criação do nome para a revista, criação da logomarca, planejamento das editorias, produção textual, criação de anúncios publicitários, produção das fotografias, ilustrações e padrão gráfico foram realizados durante na disciplina.

Quadro 1 - Tabela de distribuição dos conteúdos prévios nas disciplinas.

\begin{tabular}{|l|c|c|}
\hline \multicolumn{1}{|c|}{ CONTEÚDOS } & PUBLICIDADE E & JORNALISMO \\
\hline $\begin{array}{l}\text { Utilização dos elementos visuais } \\
\text { na composição das páginas }\end{array}$ & Direção de Arte I & - \\
\hline Tratamento da imagem & Direção de Arte II & - \\
\hline Manuseio de equipamentos & Computação Gráfica & - \\
\hline $\begin{array}{l}\text { Interpretação e criação da } \\
\text { imagem }\end{array}$ & Semiótica & $\begin{array}{c}\text { Introdução à } \\
\text { Fotografia }\end{array}$ \\
\hline Composição da imagem & Fotografia Publicitária & Semiótica \\
\hline & - & Fotojornalismo \\
\hline Produção textual & - & Jornal Laboratório. \\
\hline
\end{tabular}

Fonte: Autoria própria.

Importante ressaltar que apesar dos alunos desenvolverem atividades distintas para realização do projeto, as aulas e exercícios preliminares permitiram o nivelamento para aquisição da linguagem técnica além da compreensão teórica e prática da diagramação. Para isso foi realizada atividade de análise de uma publicação e exercícios práticos individuais durante a primeira unidade, nos meses de agosto e setembro, visando facilitar o diálogo entre os alunos durante o processo de trabalho. 
A atuação do professor no planejamento das atividades norteou o desenvolvimento do projeto. As etapas de trabalho foram pré-definidas em um cronograma desenvolvido com as equipes que auxiliaram as decisões criativas do início ao final do projeto, a exemplo dos mood boards: painéis de inspiração representados por uma colagem, atualmente digital, de imagens referenciais com propósito de transferir para o modo visual a proposta elaborada mentalmente. Os painéis mood board podem ser temáticos e informam inspirações acerca de cores e texturas, tipologia, linhas, formas e volumes escolhidas pela equipe para desenvolvimento do projeto (Fig.1).

Figura 1 - Painel de inspiração da Revista No Tom

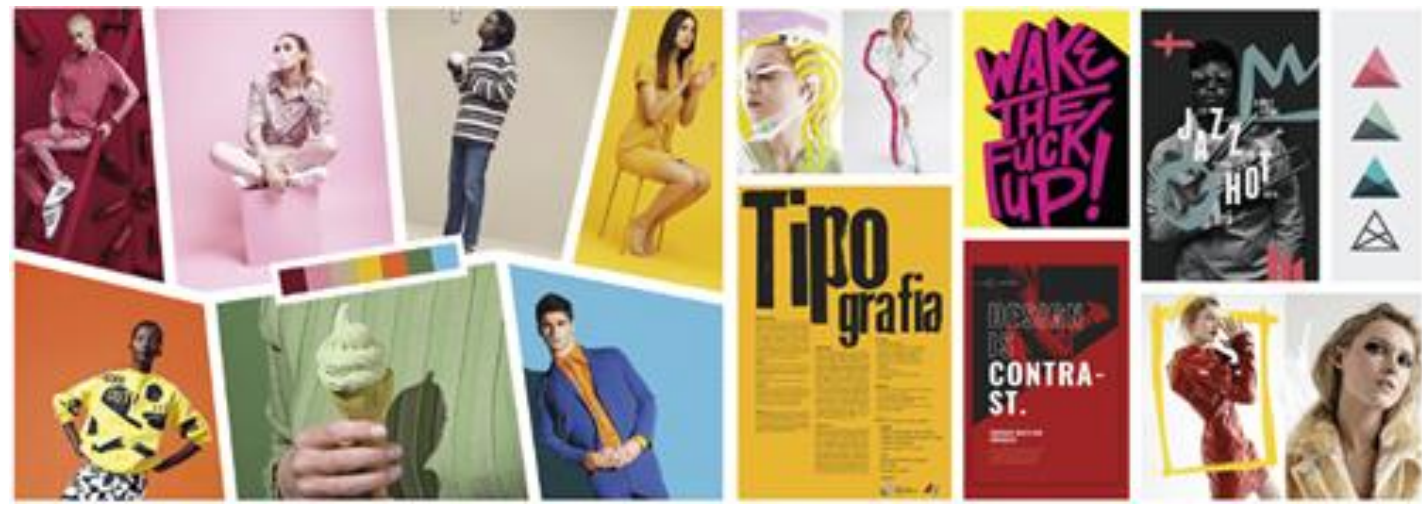

Fonte: Revista No Tom (2020)

São apresentados neste artigo dois projetos: a Revista No Tom (Fig.2), que atende o segmento de música e a Revista Provoke (Fig.3), que atende o segmento de Moda Urbana. Os dois projetos foram concebidos conceitualmente sob a valorização da identidade cultural negra e da periferia, combinando elementos estéticos do design contemporâneo. 
Figura 2 - Revista No Tom

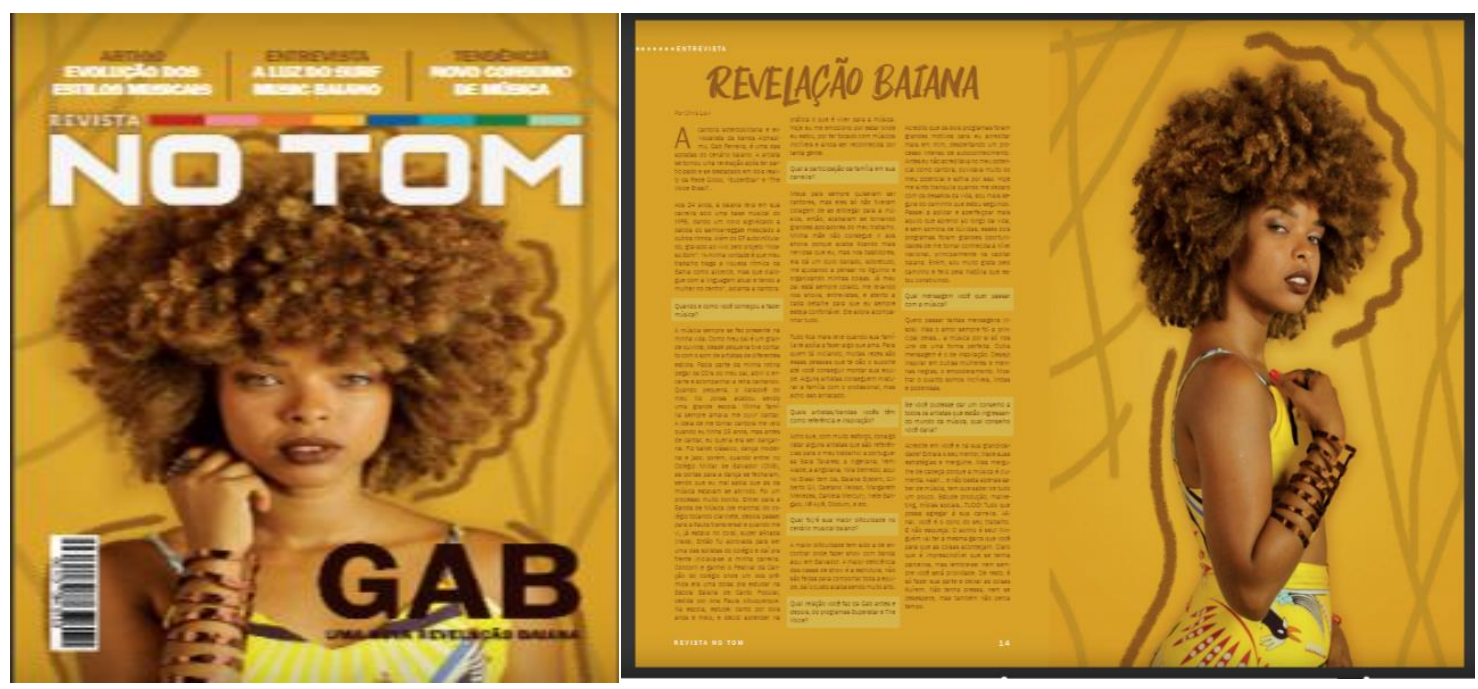

Fonte: Revista No Tom (2020)

Figura 3 - Revista Provoke
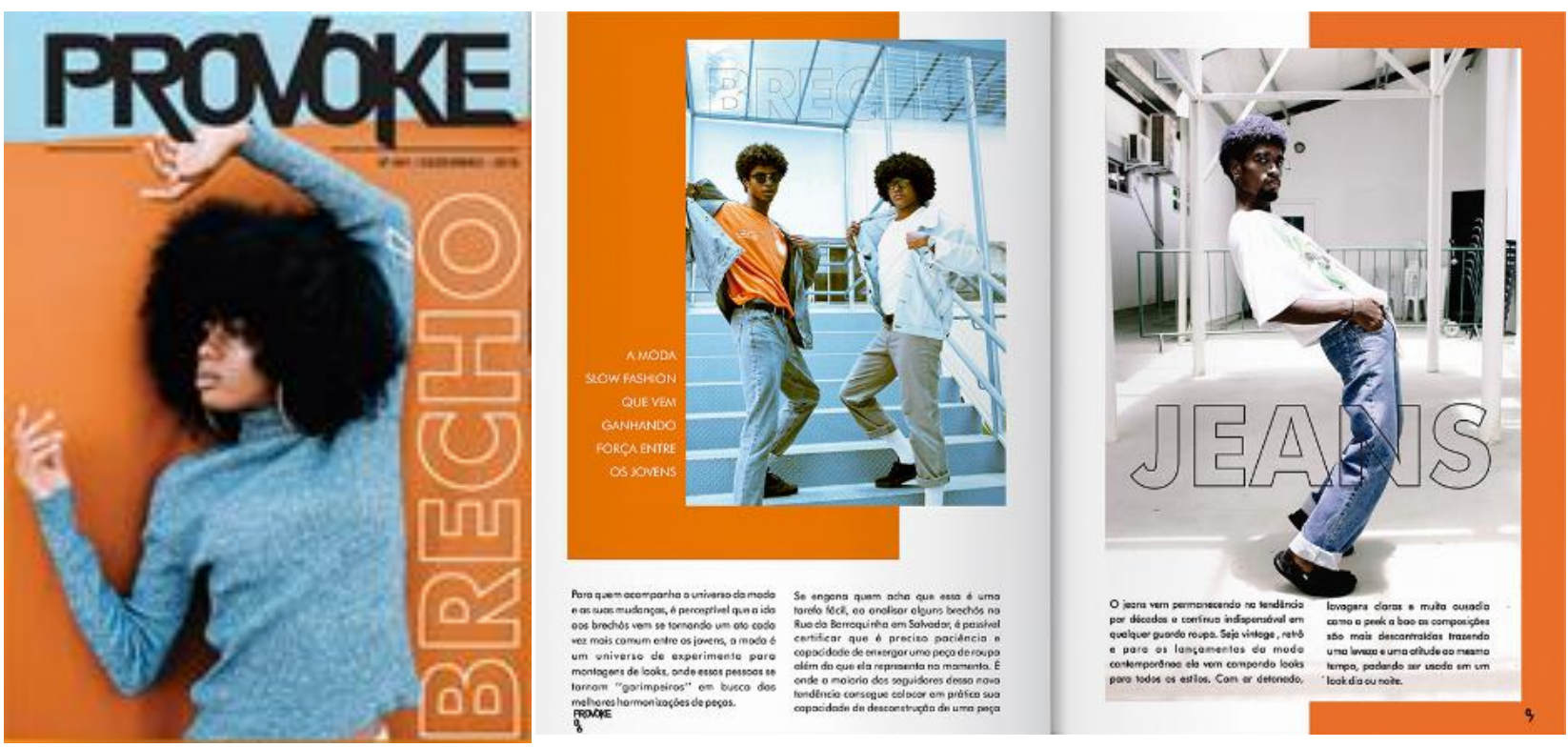

Fonte: Revista Provoke (2020)

A autonomia dada ao processo criativo e definição de conteúdo permitiram o cruzamento de referências culturais de enorme sentido existencial, o que fortaleceu o envolvimento dos alunos no projeto, especialmente no desejo de serem fiéis à proposta desenvolvida no planejamento gráfico, primeira etapa do trabalho. 
A conexão subjetiva com o tema permitiu forte compromisso com o resultado final e reiterou o exercício do rigor técnico, competência indispensável à atividade profissional em qualquer área.

Assim, vale ressaltar que os projetos avançaram, por decisão dos estudantes, os parâmetros definidos na disciplina para o projeto gráfico: a revista No Tom estendeu o conceito de representatividade incluindo-a no contexto dos seus anúncios publicitários (Fig.4), enquanto a Revista Provoke, sob conceito de movimento e urbanidade, convidou dançarinos do grupo de dança da Fundação Cultural do Estado da Bahia para uma sessão de fotos nas dependências da UNIFTC-Campus Paralela, incorporando ao desafio do projeto uma intencionalidade do corpo representado pelo movimento (Fig.5). Ressalta-se também o desafio da experimentação de variar a disposição das imagens na diagramação das páginas. Estas são possibilidades estéticas alcançadas pelo diálogo e pesquisa, superando a aplicação dos conceitos estritamente técnicos da diagramação e produção editorial.

Figura 4 - Anúncio de página simples da Revista No Tom

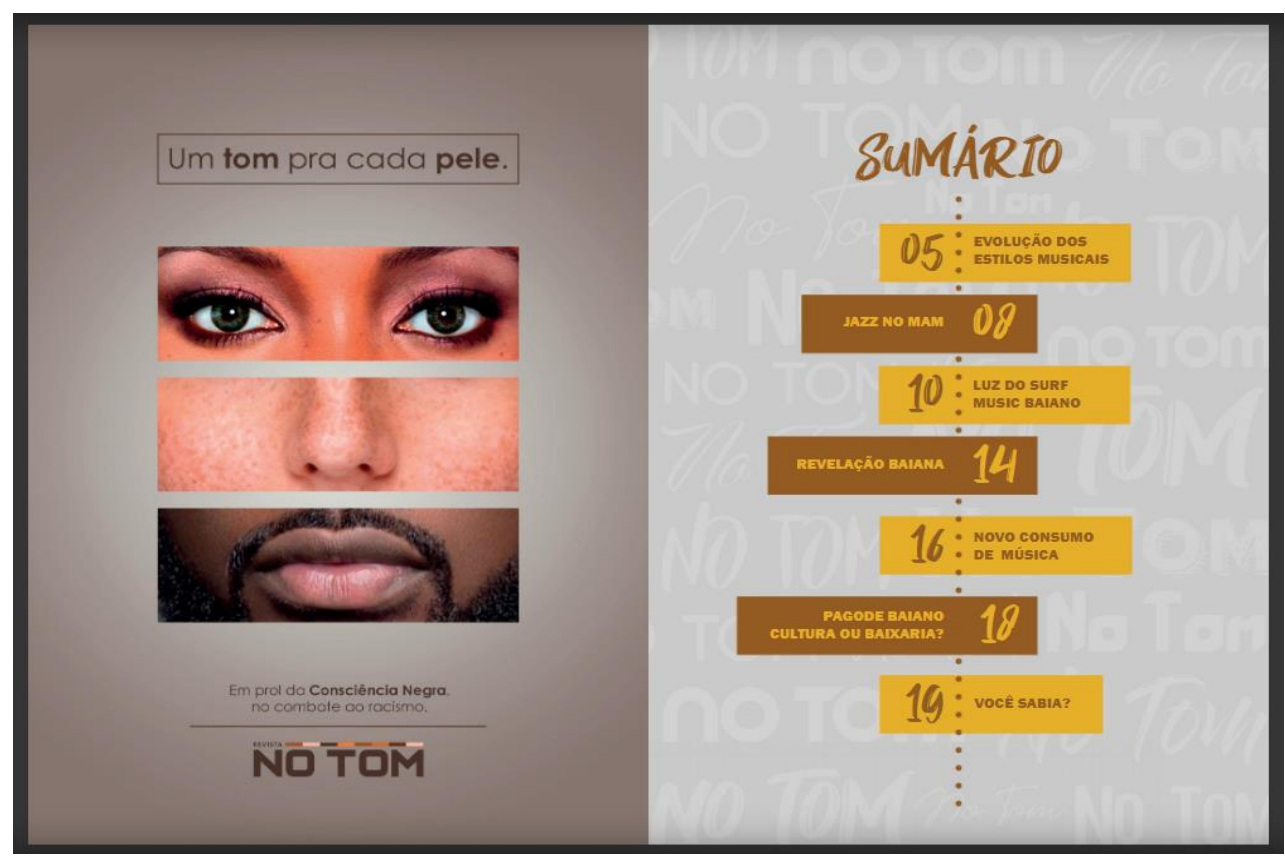

Fonte: Revista No Tom (2020) 
Figura 5 - Editorial de Moda da Revista Provoke

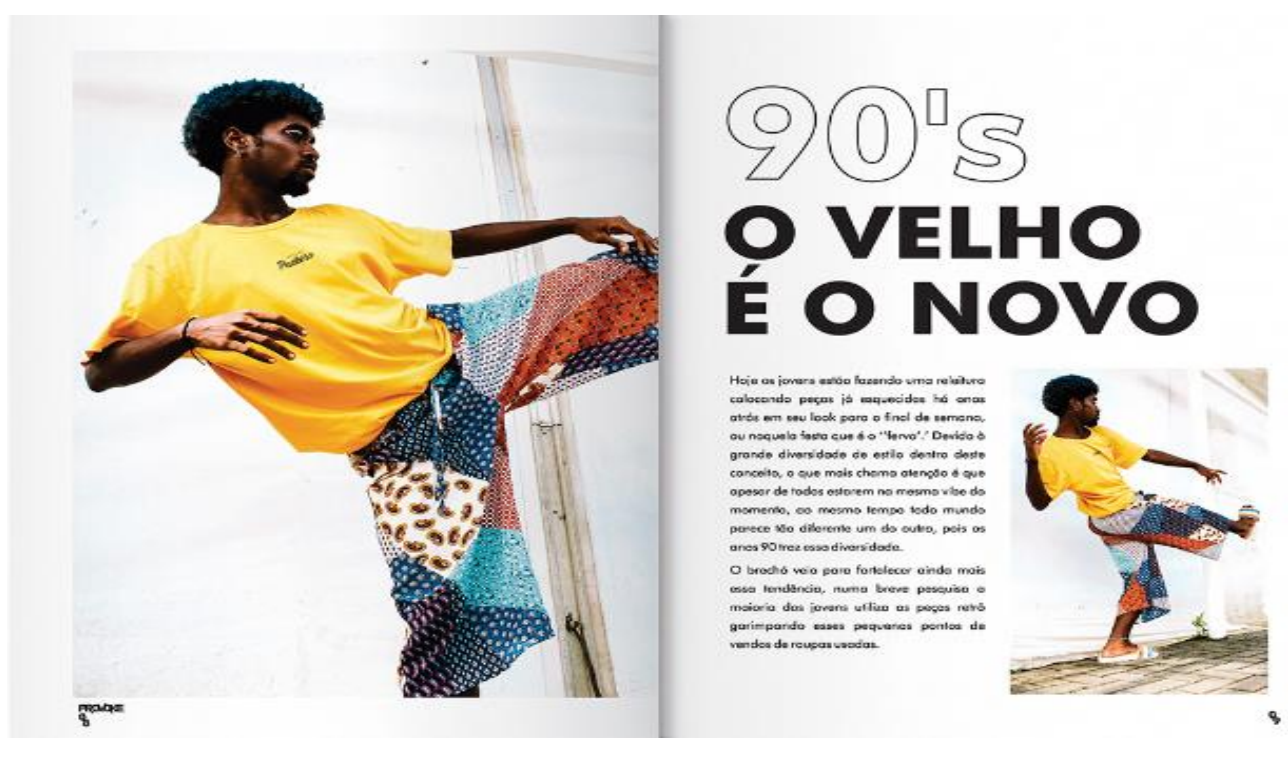

Fonte: Revista Provoke (2020)

Figura 6 - Editorial da Revista Provoke
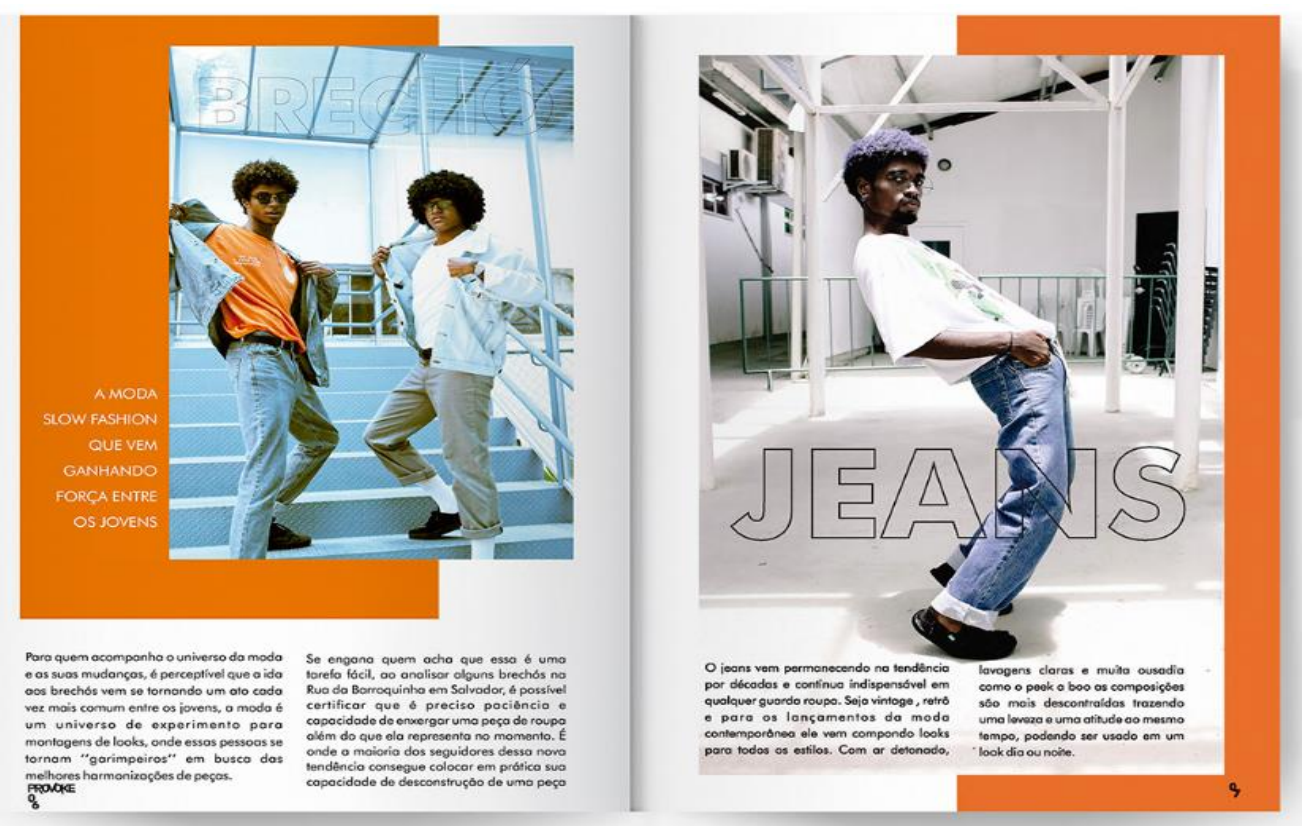

Fonte: Revista Provoke (2020) 


\section{Considerações finais}

O desenvolvimento de projetos de comunicação que permitem aos alunos a promoção da representatividade cultural da periferia contribui para o processo de reconstrução da identidade étnico-racial.

Tais produtos refletem a pluralidade da cultura afro-brasileira e ao legitimar o processo de afirmação de identidade étnico-racial fortalecem o vínculo do estudante com a academia, espaço que ainda causa estranheza e desconforto pelo histórico de segregação dos espaços considerados tradicionalmente como de produção e de aquisição de conhecimento.

A experiência acadêmica em comunicação social deve fomentar a autonomia e a autoria como processos naturais de reconfiguração dos espaços midiáticos uma vez que a sociedade globalizada disponibiliza tecnologias para os mais diversos produtos culturais.

Representatividade é um conceito amplo e multifacetado que oferece sentido existencial, de modo que pode ser considerado um estímulo à reestruturação de conceitos do aprendiz, conectando-o com novos campos do saber para difusão da identidade cultural. Sendo assim, no conceito ausubeliano, a representatividade pode se relacionar com novos conceitos de modo a ancorar novos conteúdos permitindo aprendizagem significativa.

\section{Referências}

AUSUBEL. P. D. Aquisição de retenção de conbecimentos: Uma perspectiva cognitiva. $1^{a}$ Edição. Lisboa. Plátano Edições Técnicas, 2001.

CANNEN, A. Relações raciais e currículo: reflexões a partir do multiculturalismo. In: OLIVEIRA, I. (Org.) d. Niterói: EduFF, 2001b, vol.3, p.63-77.

HUTCHEON, Linda. Poética do pós-modernismo: história, teoria e ficção. Rio de Janeiro: Imago Ed., 1991.

MOREIRA, M. A. Aprendizagem Significativa Crítica. In: NOVAK, J. D. et al. Teoria da Aprendizagem Significativa: Contributos do III Encontro Internacional sobre Aprendizagem Significativa. Penche, 2000. Cap.5, p.121-134.

NETO, J. A. da S. P. Teoria da Aprendizagem significativa de David Ausubel: perguntas e respostas. Rev. Série-Estudos, Campo Grande, 21, p.117-130, jan-jun, 2006.

SILVA, Mariana Gesteira da. As favelas no cinema. In: AVELLAR, José Carlos (Org.). Cadernos da Escola de Cinema Darcy Ribeiro, Rio de Janeiro, 2004. 
SILVA, Mariana Gesteira da. Discursos sobre a miséria e a exclusão no cinema: o caso do filme 5Xfavela, agora por nós mesmos. 2013, 78 f. Dissertação (Mestrado em Educação, Cultura e Comunicação) - Faculdade de Educação da Baixada Fluminense, Universidade do Estado do Rio de Janeiro, Duque de Caxias, 2013.

REVISTA NO TOM. Disponível em:

<https://www.behance.net/gallery/76674171/Diagramacao-Revista-No-Tom>. Acesso em: 19 nov.2020.

REVISTA PROVOKE. Disponível em: <https://www.behance.net/gallery/82186825/DIAGRAMACAO-REVISTA-PROVOKE>. Acesso em: 19 nov.2020. 